\title{
Study on Difficulties and Response Strategies of the Career Development of Young Teachers in Sichuan University of Arts and Science
}

\author{
Xiaoyi Liu \\ School of Finance and Management, Sichuan University of Arts and Science, Dazhou, China \\ Email: 1xy_423@163.com
}

How to cite this paper: Liu, X. Y. (2020). Study on Difficulties and Response Strategies of the Career Development of Young Teachers in Sichuan University of Arts and Science. Open Journal of Business and Management, 8, 2402-2408.

https://doi.org/10.4236/ojbm.2020.86148

Received: September 16, 2020

Accepted: November 6, 2020

Published: November 9, 2020

Copyright $\odot 2020$ by author(s) and Scientific Research Publishing Inc. This work is licensed under the Creative Commons Attribution International License (CC BY 4.0).

http://creativecommons.org/licenses/by/4.0/

\begin{abstract}
As the main human resource factors of education and teaching, young teachers in colleges and universities have heavy teaching and research tasks, encounter difficulties such as difficult professional title evaluation, economic income lower than expected value and long-term physical and mental sub-health. The solving of these problems is related to the scientific, healthy and long-term development of colleges and universities. This paper first analyzes the current situation of teaching and development difficulties of young teachers in Sichuan University of Arts and Science, explores the strategies to overcome the teaching development difficulties of young teachers in the university, and proposes that young teachers should influence students with excellent personality charm and the university should establish a more reasonable, perfect and fair salary and professional title evaluation system, so as to improve the interest and enthusiasm of young teachers in our university in teaching and scientific research and promote their healthy growth.
\end{abstract}

\section{Keywords}

Young Teachers in Colleges and Universities, Difficulties of Teaching, Breakthrough Strategies

\section{Introduction}

As the hard core and an important part of teachers in Sichuan University of Arts and Science, young teachers account for more than $60 \%$. Their quality and work enthusiasm directly affect and restrict the teaching quality of the university. As the new blood of the teaching staffs, young teachers in colleges and universities have greatly improved in terms of educational background, major and learn- 
ing-origin structure. However, in the actual development, young teachers in Sichuan University of Arts and Science have many difficulties of career development from teaching and survival and development. How to overcome their difficulties in work and life, help young teachers grow up healthily and build a young teacher team with strong professional thinking, high teaching ability and higher scientific research level is undoubtedly a strategic project that must be paid attention to by Sichuan University of Arts and Science.

\section{Current Situation of Difficulties of the Career Development of Young Teachers in Sichuan University of Arts and Science}

The career development of young teachers in colleges and universities refers to the process in which their professional ability, teaching experience, professional title and living conditions change with time. As professional and technical personnel, young teachers in colleges and universities are full of expectation and enthusiasm for work and life when they become teachers, especially for young teachers in Sichuan University of Arts and Science in the remote mountainous area. They have the following development difficulties.

\subsection{Teaching Difficulties of Young Teachers in Sichuan University of Arts and Science}

\subsubsection{Students Are Not Interested in Listening the Teachers}

Teaching is a complex practical activity and a two-way interaction process. If you face a group of students who have no expression, play mobile phones and play games, even teachers with high professional quality can't teach with passion. According to the author's teaching experience in the past ten years, students in Sichuan University of Arts and Science can be divided into the following levels based on their state when they listen to teachers. More than $95 \%$ of freshmen are active and serious in class. Sophomores have been familiar with university life for a year, and they have no fresh sense of university. About 30\% of them are not active or serious in class and occasionally chat with their deskmates. Junior students pay more attention to courses related to postgraduate entrance examination, civil service examination and employment, instead of study. They will focus on these courses, and just cope with irrelevant courses. The senior students in our university almost have no class. They had classes in the past. The attendance rate was only $10 \%$. (Data source: a survey on class attendance of college students in Sichuan University of Arts and Sciences). Facing this situation, few teachers have good psychological quality and teach without affecting their mood. In the Internet era, there are too many temptations in the outside world. In particular, the information on the mobile phone is too attractive. Teachers have to face the embarrassing situation of "striving for favor" with the mobile phones. This is a difficult problem for teachers in the Internet era. How to overcome this difficulty, attract students' attention and improve students' in- 
terest in learning is a problem worthy of consideration by teachers in colleges and universities.

\subsubsection{Lack of the Motivation of Career Development}

Teachers' pursuit of excellent teaching is the internal driving force of their own development. However, how to attract teachers and students to actively participate and improve teaching enthusiasm and motivation is a major practical issue for young teachers in our university. First, for a long term, China's higher education has paid more attention to scientific research than teaching. Colleges and universities have generally linked the actual interests of teachers, such as position appointment, professional title evaluation and allowance and reward, with the number of scientific research projects, subjects and published papers of teachers. In recent two years, the title evaluation documents of our university have been reformed. The evaluation of teaching professors and teaching associate professors is added, but the evaluation conditions are very strict. For example, for teaching professors, the minimum number of class hours should be 360 per year. They should win provincial and ministerial-level teaching achievement awards and guide students to participate in the national college student competition sponsored by the Ministry of Education of the People's Republic of China. It is difficult to win a prize in these competitions, so few teachers apply for teaching professors or associate professors every year. They can only apply for the senior teaching and research titles. Therefore, young teachers who have a lot of classes and no time for scientific research cannot apply for higher titles, and their salaries are low, which greatly reduces their teaching motivation and enthusiasm. How to achieve a balance between teaching and scientific research, how to arouse teachers' enthusiasm and motivation in teaching and how to overcome the teaching difficulties are problems worthy of consideration by both the university and teachers.

\subsection{Survival and Development Difficulties of Young Teachers in Sichuan University of Arts and Science}

In the eyes of many outsiders, college teacher is a relaxed, decent and high-income job, but actually they have a lot of responsibilities and a big pressure, especially for teachers in remote mountainous areas. Our university is under the jurisdiction of Sichuan Provincial Department of Education. The level sounds high, but Sichuan Province and Dazhou do not attach much importance to it. This is mainly reflected by the fiscal appropriation of the government. The salaries of teachers in our university are low. For example, the income of a graduate student newly recruited by our university is about RMB 4000, that of a lecturer is about RMB 5000, that of an associate professor is more than RMB 6000, and that of a professor is more than RMB 8000. (Data source: planning and Finance Department of Sichuan University of Arts and Sciences). The number of class hours should be at least 12 a week. If the number of class hours is below 12, 
they cannot get such salaries and there is no year-end bonus. If your professional title does not change greatly, your income will not change for 10 years. With the continuous rising of prices, the cost of living consumption is higher and higher, and the pressure of life is great. Many teachers in our university feel that their income is lower than the expected value and that of their classmates who work in other units. Some teachers even take part-time income as their main source of income. They have the realistic needs of survival and development (Liu, 2020), love and marriage and purchasing of houses and cars, as well as pressure of teaching and scientific research assessment. Without good career planning, it is easy for them to have job burnout early.

\section{Strategies to Overcome Career Development Difficulties of Young Teachers in Sichuan University of Arts and Science}

A series of phenomena of the career development difficulties of young teachers in colleges and universities can be summarized as following aspects. First, teaching skills. Second, teaching motivation. Third, survival and development. Therefore, in order to overcome the career development difficulties of young teachers, we need to start from these aspects and overcome difficulties in terms of skill cultivation, motivation stimulation, system guarantee, etc.

\subsection{Create Teaching Situation and Activate Classroom Atmosphere}

Confucius, a great thinker and educator, said: "those who know are not as good as those who are good, and those who are good are not as good as those who are happy." Interest is the internal force to promote learning, and students' interest in learning is a powerful driving force for learning. Effective teaching situation, condense students' attention, arouse students' curiosity and creativity, can stir the string of students' thinking and stimulate their thinking sparks. Therefore, teachers should strive to create a teaching atmosphere in teaching, so that students can actively speak and express their opinions under the guidance of teachers. Therefore, when preparing lessons, we should design some difficulties according to the differences of students' actual level, and ask for other problems in detail. According to the different requirements of different students, in the classroom, according to the different personality characteristics of students, we should seize the opportunity to stimulate and inspire in time, and create conditions for students' thinking and words, provide opportunities for them to have the desire to express problems, so as to stimulate interest in learning and activate the classroom atmosphere.

As Sichuan University of Arts and Science adheres to the goal of cultivation of applied talents with "three hearts, four abilities and five combinations", we should pay attention to the development of students' learning ability, practical ability and innovation ability in classroom teaching. At the same time, we should 
constantly innovate education methods, use advanced teaching tools, be good at dealing with and coordinating the relationship with students, and strive to create a harmonious (Dong, Gu, \& Wang, 2019), pleasant and relaxed classroom atmosphere. In this way, a teacher will attract students to approach him/her and unconsciously learn from him/her like a magnet, and effectively prevent students in our university from playing mobile phones, chatting, skipping classes, etc.

\subsection{Strengthen the Career Planning Guidance}

We should help young teachers in our university to establish the career development goals and paths. The career development plan is made to guarantee the goals and paths of career development. The formulation of the career development plan is the basis and premise of ensuring the career development. Through the scientific career planning, we can achieve several effects. First, we can help young teachers to recognize themselves, and find out their own personality traits, strengths and weaknesses, potential development space and trend and career orientation; second, on this basis, we can help young teachers reasonably evaluate the gap between their ideals and reality and establish the goals of career development according to their own comprehensive conditions; third, through the process of career planning (Huang, 2018), we can clarify the development ideas, make action plans, give full play to the potential of individuals, and move towards the established goals; fourth, with clear career planning, we can help to improve the sense of self-efficacy of young teachers and relieve job burnout (Wu, Gong, \& Zhu, 2020). When young teachers have clear self-development goals, they will have a sense of enrichment and satisfaction at the spiritual level, and have a clear expectation for each stage of development, so as to strive to achieve, grasp and create development opportunities, broaden the channels of career development and finally realize their own aspirations.

\subsection{Improve the Salary and Welfare of Young Teachers}

How to improve the job stability, salary and welfare of university teachers, especially young teachers is a sensitive problem faced by many colleges and universities. Our university is a public university. The salary and welfare are fully funded by the provincial finance and supervised by various national and local departments. We cannot adjust the salary and distribute welfare at any time. However, our university can adjust the performance distribution scheme appropriately with unchanged total amount, so as to increase the salary of the front-line young teachers. For example, the minimum number of class hours in our university is 230. According to the survey, more than $80 \%$ of teachers say that this standard is very high, which can be appropriately reduced by a half, so as to increase the income of young teachers. In addition, in recent years the funding for scientific research projects in our university is also one of the incomes of some teachers. 
Now, it is easier to apply for research projects than before, but the reimbursement of expenses is difficult. For example, most teachers of liberal arts projects can only apply for projects with funds of RMB 3000 - 10,000, but they still have to find many invoices for reimbursement. It is troublesome to collect invoices. It is recommended that for projects with less funds (such as RMB 20,000 the project funds should be directly allocated to the teachers' salary account as long as the project is completed normally, which can improve the motivation of teachers to do scientific research. In addition, there is no year-end target assessment award in our university, which is criticized the most by many young teachers. Most primary and middle school teachers and teachers of vocational colleges have target awards. It is suggested that our university can apply to Dazhou or Sichuan Provincial Education Department (Li \& Guo, 2019). Considering the actual conditions of young teachers in our university, not to mention paying more than other colleges and universities, we should at least maintain the similar salary, welfare and year-end bonus as other colleges and universities at the same level.

\section{Conclusion}

In the era of "Internet+", information is transparent and spread very fast. Teachers have many choices, but it is also very important for a university to maintain the relative stability of talents. As the employer of teachers, the harbor to rely on by teachers, and the judge of professional titles and issuance of salaries of teachers, colleges and universities should consider the needs and interests of various groups. It is really difficult to satisfy the interests of teachers at different levels, with different professional titles and at different positions. However, how to keep the distribution process relatively just fair and reasonable and consider the interests of young teachers is a problem worthy of consideration. Young teachers should also have certain professional ethics, maintain a good attitude, and pass on positive emotions to students. We should not only ask the university to increase salary and welfare, but also love the university, work and life, have enthusiasm for teaching, and be worthy of the good and stable teaching and working environment provided by the university.

\section{Fund Project}

This paper is funded by the educational teaching research and reform project at the university level of Sichuan University of Arts and Science from 2020 to 2022 (project number: 2020JZ032) and the first-class course project of Sichuan University of Arts and Science in 2020 (project number: 2020KCC002).

\section{Conflicts of Interest}

The author declares no conflicts of interest regarding the publication of this paper. 


\section{References}

Dong, J. C., Gu, F., \& Wang, Z. (2019). Cultivation of the Personality Charm of Teachers in Colleges and Universities in the Network Era. Education and Teaching Forum, 1, 24-26.

Huang, T. (2018). Analysis on the Difficulties and Response Strategies of the Development of Young Teachers in Colleges and Universities. Journal of North China University of Water Resources and Electric Power (Social Science Edition), 12, 115-117.

Li, J., \& Guo, M. L. (2019). Difficulties and Response Strategies of the Teaching Development of Young Teachers in Local Colleges and Universities. Higher Education Forum, No. 8, 59-61.

Liu, Y. L. (2020). Realistic Difficulties and Path Selection of Teaching Development of Young Teachers in Local Colleges and Universities under the background of Deepening the Evaluation Reform-Take the Practice of University A in Beijing as an Example. Journal of Huanghe $S \& T$ University, No. 6, 77-81.

Wu, B. B., Gong, J., \& Zhu, J. J. (2020). Research on the Existing Problems and Response Strategies of the Evaluation of Professional Titles of Teachers in Colleges and Universities. Education Science \& Culture, 3, 11-12. 